\title{
¿INMIGRANTES, LA REPRESENTACIÓN DEL “MAL”? A PROPÓSITO DE HAITÍ Y REPÚBLICA DOMINICANA*
}

\section{Yennesit Palacios Valencia**}

Fecha de recibido: 12 de junio de 2014.

Fecha de aprobado: 22 de agosto de 2014.

Artículo de reflexión

Forma de citación: Palacios, Y. (2014). ¿̇Inmigrantes, la representación del "mal"? A propósito de Haití y República Dominicana. Revista Prolegómenos. Derechos y Valores, 17, 34, 162-182.

\section{Resumen}

El estigma que persigue a cientos de inmigrantes es la idea de encarnación del mal, fobotipo que perdura en décadas actuales pese a las arbitrariedades evidenciadas a lo largo de la historia. Al respecto, en este escrito se analizarán las arduas tensiones arraigadas desde decenios pasados en las regiones caribeñas de República Dominicana y Haití, pues se han originado tensiones irreconciliables que se traducen en el desconocimiento de los derechos humanos de descendientes haitianos por pertenecer al grupo de los "negros-extraños", objeto de malestar. Conclusión que se deriva de la apreciación de la inmigración como un fenómeno peligroso por la presencia de un cierto círculo social catalogado como "enemigo". Por ello, el objetivo es evidenciar cómo se violan los derechos humanos de ciertos sujetos al ser estigmatizados por pertenecer a un colectivo; fenómeno que hoy ocurre de modo paradigmático con la inmigración. Líneas que parten de una investigación cualitativa de naturaleza histórico-analítica, pues el recorrido al pasado es necesario para establecer relaciones de causa-efecto y conectar los factores que llevan a la permanencia de estereotipos que han impulsado la aplicación ex post facto de normatividad con efectos retroactivos devastadores.

\section{Palabras clave:}

Derechos humanos, Haití, República Dominicana, inmigrantes, enemigo, mal.

* Este artículo es el resultado de distintas políticas que, desde el análisis propuesto, vinculan a la población inmigrante dentro de un determinado grupo social como enemigo. Lo cual se presenta como aporte investigativo de la tesis doctoral que lleva por nombre "Derecho penal del enemigo: discurso antagónico a la defensa de los derechos Humanos". Investigación terminada en la Universidad Pablo de Olavide de Sevilla, España.

* Abogada de la Universidad de San Buenaventura Seccional Medellín. Magíster y PhD en Derechos Humanos y Desarrollo de la Universidad Pablo de Olavide de Sevilla. Magíster en Relaciones Internacionales de la Universidad Internacional de Andalucía. Especialista en Cultura Política de la Universidad Autónoma Latinoamericana de Medellín. Ha sido docenteinvestigadora en el área de Derechos Humanos en la Universidad Santo Tomás de Medellín y de la Universidad de San Buenaventura. E-mail: yennesit.palacios@gmail.com. 


\title{
¿IMMIGRANTS, REPRESENTATION OF EVIL? REGARDING HAITI AND DOMINICAN REPUBLIC
}

\begin{abstract}
The stigma thatchaseshundreds of immigrants is the idea of evil incarnation, fobotypewhichlasts in currentdecadesdespite the arbitrariness made clearalonghistory.Regardingthissubject, the hard disputes settled down sincepastdecades in the caribbeanregions of DominicanRepublic and Haitiwillbeanalyzed in thiswriting, becauseirreconcilable tensions have grown and this has produced the unacknowledgement of humanrights on haitian descendants for belonging to the group of "weird-blacks", synonym of uneasiness. This conclusion derivesfrom the appreciation of immigration as a dangerousphenomenonbecause of the presence of certain social circlecategorized as "enemy". Therefore, the objective is to makeclear how humanrights of some people are violatedwhenthey are stigmatized for belonging to a group; today, thisphenomenonhappens in a paradigmaticwaywith immigration. Lines thatbeginwith a qualitative investigation of historical-analytic nature, because a review to the pastisnecessary in order to establish relations of cause-effect and connect the factorswhichtake to the continuity of stereotypesthat have motivated the application ex post facto of ruleswithdevastatingretroactiveeffects.
\end{abstract}

\section{Key words:}

Humanrights, Haiti, DominicanRepublic, immigrants, enemy, evil.

\section{¿IMIGRANTES, A REPRESENTAÇ̃̃O DO "MAL? A PROPÓSITO DE HAITI E REPÚBLICA DOMINICANA}

\begin{abstract}
Resumo
O estigma que persegue a centos de imigrantes é a ideia de encarnação do mal, fobo tipo que perdura em décadas atuais a pesar das arbitrariedades evidenciadas ao longo da história. Ao respeito, neste escrito serão analisadas as árduas tensões arraigadas desde decénios passados nas regiões caribe de República Dominicana e Haiti, pois tem se originado tensões irreconciliáveis que são traduzidas no desconhecimento dos direitos humanos de descendentes haitianos por pertencer ao grupo dos "negros-estranhos", objeto de mal-estar. Conclusão que se deriva da apreciação da imigração como um fenómeno perigoso pela presencia dum certo círculo social catalogado como "inimigo". Por isso, o objetivo é evidenciar como são violados os direitos humanos de certos sujeitos ao ser estigmatizados por pertencer a um coletivo; fenómeno que hoje ocorre de modo paradigmático com a imigração. Linhas que partem duma investigação qualitativa da natureza histórico-analítica, pois o recorrido ao passado é necessário para estabelecer relações de causa-efeito e ligar os fatores que levam à permanência de estereótipos que tem impulsionado à aplicação ex pôs fato de normatividade com efeitos retroativos devastadores.
\end{abstract}

\section{Palavras chave:}

Direitos humanos, Haiti, República Dominicana, imigrantes, inimigo, mal. 


\section{INTRODUCCIÓN}

Y el odio más intenso está tan arraigado, que impone el silencio y convierte la vehemencia en un rencor constructivo, en una aniquilación imaginaria del objeto detestado, algo así como los ritos ocultos de venganza con los cuales los perseguidos desahogan terriblemente su cólera.

George Eliot (Daniel Deronda, citado en Scott, 2000, 23).

Como punto de partida debe precisarse que este aporte investigativo tiene por objetivo evidenciar cómo se han desarrollado políticas denigrantes, con tachas y etiquetas que violan los derechos humanos de ciertos sujetos al ser estigmatizados por pertenecer a un colectivo; fenómeno que hoy ocurre de modo paradigmático con la inmigración. Líneas que parten de un soporte doctrinal, histórico y jurisprudencial, para contrastar cómo son afectados desde tiempo atrás colectivos cuya presencia se identifica como peligrosa, al punto que la historia demuestra que recurrir al exterminio ha sido una usanza para todo aquel que sea portador de "peligrosidad".

En este recorrido será crucial el estudio de la era del dictador Trujillo en República Dominicana (1930-1961) hasta llegar a nuestros días, para visibilizar algunas dinámicas que se relacionan directamente con violaciones masivas de derechos humanos, por la creación de normativas excluyentes aún soportadas en Estados democráticos. Por tanto, el artículo se sustenta en una investigación cualitativa de naturaleza histórico-analítica, ya que es obligatorio volver al pasado para analizar el vaivén de procesos sociales que le han negado el sentido "vivo" a los derechos humanos, dada la permanencia de estereotipos que impulsan la aplicación ex post facto de normatividad, afectando en determinados contextos a poblaciones de inmigrantes, esencialmente por la presencia de elementos culturales, políticos y económicos, que muy posiblemente siguen condicionando los pilares en los cuales se sustenta la infinidad de tratados internacionales sobre derechos humanos.

Con este recorrido se demostrará que los flujos migratorios -dadas las mayúsculas tensiones existentes entre Europa y África con la tradicional concepción de inmigrantes indocumentados, "ilegales" o sin papeles-, no pueden ser vistos solo desde el "viejo mundo", también se concentran en países latinoamericanos, de ahí que el fobotipo (Lucas, 2005) en la "persona del inmigrante", es un ejemplo, por antonomasia, que puede verse reflejado en República Dominicana por el rechazo que está condenando a una población estigmatizada con un nombre y etiqueta propia, la historia "manchada" con el nacer haitiano -los indignos, inicuos e indeseados-, que no merecen el reconocimiento como personas en derecho. Pues aún las particularidades que unen a estas regiones caribeñas, para no ser "negro engendro del mal" hay que diferenciarse de los haitianos a toda costa, siendo preferible la pérdida de identidad y no reconocerse como afrodescendiente-sobra ver el calificativo estampillado en las cédulas de ciudadanía, que opta por denominar el color de la piel como indio-, antes que ser identificado como negro, pues aquel, será siempre el haitiano y nunca el dominicano.

Herencia auténtica que viene marcada desde la era de Trujillo catalogada como una de las más sangrientas del continente americano (Moya, 2001b; Sención, 2012), presencia que estuvo latente hasta el momento de su muerte en 1961. Sólidas raíces que, quizá, son la consecuencia directa de épocas remotas de conflictos por territorio ante la existencia de naciones esclavistas que, precisamente, fueron la razón originaria para la institucionalización de la violencia.

Situación que viene pisando fuerte desde décadas pasadas ante el fracaso en 1844, inter alias, de mantener unificado a Haití y República Dominicana. Efecto que hoy se traslada a los estrados judiciales y no logra superar las heridas de antaño, pues según el Tribunal Constitucional de República Dominicana (TCRD) -en relación preponderante con los dominicanos no recono- 
cidos como tal, por tener sangre haitiana-, no basta con nacer en territorio dominicano para recibir de modo automático la nacionalidad, circunstancia que incitó una reforma obligada a la Constitución en el año 2010, para poder expulsar y negarle los derechos humanos a colectivos que durante décadas han vivido y nacido siendo dominicanos. Caso en el cual como se demostrará en este escrito, no se habla de inmigrantes en la "ilegalidad", sino de xenofobia, "pues lo que prima no es el comportamiento sino la pertenencia a un colectivo" (Portilla, 2007, p. 106), boom propagandístico que populariza la fobia al inmigrante, homo sacer (Agamben, 2010) de la modernidad, "que debe ser tratado como problema de seguridad nacional, que puede incluso alterar el equilibrio emergente" (Portilla, 2007, p. 106). Por ello se concluirá, que aún con el pasar de los años, entre Haití y República Dominicana, ha existido y existirán, tensiones irreconciliables, dado el trato peyorativo que abunda en la población para marginar y excluir la descendencia haitiana, como si fuese la mismísima encarnación del "mal".

\section{Sobre el problema objeto de estudio}

Ante los males que dicen acechar a las grandes ciudades por la visita de los "extraños a la comunidad" (Muñoz, 2002, 2002a), se irradia una alerta permanente por el supuesto peligro proyectado. Emergencia que fomenta también una sociedad disciplinar, entendida como aquella "donde el comando social se construye a través de una difusa red de dispositifs o aparatos que producen y regulan costumbres, hábitos y prácticas productivas" (Hardt \& Negri, 2000, p. 25).

Para funcionar de tal manera, se necesita generar un cierto clima de pánico difuso frente a un fenómeno presentado como peligroso y potencialmente destructivo, así como la percepción de un determinado grupo social como "enemigo" (Jakobs, 2006). Esto ocurre hoy de modo paradigmático con la inmigración (Zamora, 2005). De hecho, los occidentales temen estar siendo invadidos en la actualidad, no por ejércitos y tanques, sino por "emigrantes que hablan otras lenguas, adoran a otros dioses, pertenecen a otras culturas y que, temen, se quedarán con sus trabajos, ocuparán su tierra, vivirán del sistema de Estado del bienestar y amenazarán su forma de vida" (Huntington, 2001, p. 191). Por esta razón, la multitud reacciona rechazando, excluyendo y matando en vida al "otro", "extraño", situación mezclada de efervescencia:

A propósito de las foules de Gustave Le Bon, las masas en estado de "descarga", con su "rabia destructora", su "desintegración" y su pánico, que analiza y psicoanaliza Elías Canetti, el "fenómeno de las multitudes en estado frenético y violento", que enumera Recasens Siches, esa multitud que -explica Karl Mannheim- "puede definirse como una agregación física, compacta, de seres humanos llevados a un contenido directo, temporal e inorganizado, que en su mayoría reacciona ante los mismos estímulos y de una manera semejante" [...] Siempre "transitoria e inestable", como un accidente, una erupción (Goytisolo, 1968, pp. 18-19).

Todo esto genera en las formas modernas de democracia un retroceso incuestionable respecto de la conquista de los derechos humanos, por permitir el trato a ciertos círculos sociales como no-personas por ser los indeseados que no merecen derechos. Consecuencia directa que lleva a la creación de normativas que van en contravía de tratados sobre derechos humanos so pretexto de una presencia que se percibe como amenazante, limitando la aplicabilidad de derechos básicos de los que son titulares todos los seres humanos, precisamente porque el inmigrante en la época moderna es abiertamente el "enemigo".

\section{¿INMIGRANTE O “EXTRAÑO” A LA COMUNIDAD?}

El transcurso de la historia puede explicar cómo ha sido, y es, la suerte del débil ante el poderoso en su trato como no-persona. $\mathrm{Si}$ se hace una mirada rápida, durante el régimen de la Alemania nazi, con el desarrollo del proyecto nacional 
socialista sobre el tratamiento de los extraños a la comunidad, se definió como extraño, entre otras cosas a,

1. Quien por su personalidad o forma de conducción de vida, especialmente por sus extraordinarios defectos de comprensión o de carácter, es incapaz de cumplir con sus propias fuerzas las exigencias mínimas de la comunidad del pueblo. 2. Quien por una actitud de rechazo al trabajo o disoluta lleva una vida inútil, dilapidadora o desordenada y con ello molesta a otros o a la comunidad, o por dependencia o inclinación a la mendicidad o al vagabundaje, al trabajo ocasional, pequeños hurtos, estafas u otros delitos menos graves, o quien en estado de embriaguez provoca disturbios o por estas razones infringe gravemente sus deberes asistenciales, o por su carácter asocial o pendenciero perturba continuamente la paz de la generalidad (Muñoz, 2002, pp. 504).

Este análisis hoy fácilmente puede trasladarse al inmigrante que llega a terceros países, siendo víctima de una cultura que se percibe amenazante y se manifiesta a través de

[...] sentimientos que enmascaran el racismo latente en este discurso. Si por algo se caracteriza este nuevo racismo es porque los sujetos racistas no tienen sentimientos de odio o aversión sino de incomodidad, inseguridad $y$, en ocasiones, temor; sensaciones que provocan más la evitación del otro que no su agresión directa (Strohmayer, H., Coral, C. C., Castellanos, M. L., Ortega, I. G. B., \& Cánovas, A. P. 2005, p. 285).

Tensiones que se provocan, en gran medida, por el efecto revote de las sociedades en masas: "Las masas avanzan, las masas se extienden, las masas absorben. No importa que sean conducidas hábilmente por técnicos que las manipulen [...]. Estamos inmersos en la hora de la masa" (Goytisolo, 1968, p. 16). Al respecto, Philpp Lersch y Emil Bruner expresan que:
La masa, es pura cantidad, una acumulación o conglomerado sin trabazón interna y sin forma externa; implica la homogeneidad de sus partes componentes o, cuando menos, la insignificancia de las diferencias que pudiera existir. Masa es lo amorfo, lo que no tiene trama, urdimbre ni estructura: es la mera reunión o contigüidad de partículas iguales. Pero esta palabra, aplicada a una acumulación o conglomerado humano, ha sido empleada con diversos significados (citados en Goytisolo, 1968, pp. 16-17).

Trampa colectiva que inspira, convence y manipula, pues ila masa ha sido ya declarada la encarnación de Dios! (Goytisolo, 1968). Comprender aquello que es objeto de la observación humana es complejo, pero es un aspecto indispensable para entender porqué en la sociedad se actúa de una manera y no de otra.

Ves, papá, cuando nos ponemos a hablar sobre los extranjeros y los inmigrantes muchas palabras se repiten una y otra vez. Por ejemplo: identidad, diferencia, comunidad, etnia, discriminación, generación, gueto, integración, visibilidad, universalismo, etc. No acabo de entender lo que significa, porque lo utilizan un poco al tuntún. Sobre todo porque a veces, con las mismas palabras unos pretenden ayudar a los inmigrantes y otros quieren excluirlos. No se sí me explico [...] (Naïr, 2010, p. 90).

El teatral sentido de la masa que convoca a la expulsión, se explica desde el miedo a lo extraño, en el "juego" que el sistema mundo juega para justificar los medios y las formas de marginar; cum finis est licitus, etiam media sunt licita (cuando el fin es lícito, también lo son los medios); aforismo del teólogo alemán, Hermann Busenbaum, en su obra Medulla theologiae moralis (O'neill \& Domínguez, 2001). Máxima que en Maquiavelo sería el fin justifica los medios; pues se está ante una sociedad donde la diferenciación del otro, se legitima para repeler aquello que molesta, aquello que es indeseable, porque se conjura 
una etiqueta que subvalora y deteriora, para dividir a quien se le debe rendir respeto en sus derechos de aquel que se debe tratar como enemigo; campaña mediática disfrazada de un fin lícito, y por tanto permitido.

Efecto que tiende, y cada vez más, a evidenciarse en la underclass -fobotipo que no solo es cosa de inmigrantes-. Por el retroceso que se avizora la denominada underclass se hunde cada día en el abismo, o más bien en el submundo. Es como una especie de campaña, donde la meta es doblegar cada vez más a los excluidos y, en el peor de los casos, aniquilarlos. Esto explica que, en cada

[...] metrópoli del primer mundo, uno o varios municipios, distritos o concentraciones de viviendas sociales son conocidos y reconocidos como infiernos urbanos -habitados también por población de inmigrantes-, donde la violencia, el vicio o el abandono conforman la normalidad. Algunas adquieren incluso el estatus de encarnación nacional de todos los males y peligros que, se cree, ahora padece la ciudad dualizada (Wacquant, 2007, p. 194).

Lo anterior confirma -como en el caso del genocidio de los judíos- "que el inmigrante 'ilegal' es uno de los individuos marcados como el mal absoluto. Como un objeto del que se puede disponer sin más" (Portilla, 2007, p. 104); por tratarse simple y llanamente, de la forma legal de combatir los peligros extremos.

Ante estos invasores la tesis fundamentada por Foucault (2007) sobre el biopoder se reactiva, justificando medidas globales y de sospecha, para intervenir, vigilar y castigar (Foucault, 2002), por la cultura del peligro -que se traduce en medidas para prevenir el mal engendrado- con procedimientos de control, coacción y coerción. Aparece así, una sociedad posdisciplinaria -atravesada por una multitud productiva que escapa a las categorías disciplinarias de normalidad y patología social, conformidad y desviación, trabajo y peligrosidad, dado que puede incluirlas a todas sin dejarse identificar con ninguna de ellas-que impone lo que releyendo a (Bauman, 2001), puede definirse como un "orden sin norma" (Giorgi, 2006, p. 135).

La puesta en marcha de esta sociedad, asegurando la obediencia a sus reglas y a sus mecanismos de inclusión y/o exclusión, se logra por "medio $\mathrm{de}$ instituciones disciplinarias que estructuran el terreno social y presentan lógicas adecuadas a la 'razón' de la disciplina" (Hardt \& Negri, 2000, p. 25). En efecto, el poder disciplinario gobierna, estructurando los parámetros y límites del pensamiento y la práctica, sancionando y prescribiendo los comportamientos normales y/o desviados (Hardt \& Negri, 2000).

La desviación, según Giorgi (2006), vista en el contexto de la interacción social, es en esencia proyectada más que materializada; temida antes que deplorada; evitada antes que confrontada; prevenida antes que suprimida. Se trata de una esfera sociocognitiva completamente renovada, que emerge del confín bien demarcado que divide territorios gobernados y "otros peligrosos" (Giorgi, 2006). Lo que puede entrar en esa lógica de la desviación es infinito; empezando por todos los que no encajan en ese prototipo de persona-los otros-enemigos- hasta el clandestino inmigrante "ilegal", sin papeles, en contraposición al "amigociudadano", y por tanto digno de derechos. Ya que en tiempos actuales el inmigrante es el fiel retrato del primero a ser llamado a delinquir.

Para corroborar lo anterior, basta examinar el estudio $^{1}$ que realizó un grupo de destacados

\footnotetext{
En el mismo sentido, en una investigación desarrollada en Murcia (España), se consideró que para saber qué piensan los jóvenes autóctonos de estas localidades sobre la inmigración es mejor no preguntárselo directamente, porque en ese tema, como en muchos otros (por ejemplo la sexualidad, el dinero, la moralidad...), hay una gran distancia entre lo que se comenta en privado, solo a los más allegados, y lo que se enuncia abiertamente. Podría decirse que el lugar simbólico que ocupan los inmigrantes en el imaginario de los jóvenes españoles participantes en los grupos de discusión y entrevistas realizadas, está definido por unos extraños contornos, que hacen que dos hechos aparentemente contradictorios afecten al mismo tiempo a las poblaciones inmigrantes: la invisibilidad y la hipervisibilidad. La primera significa que a
} 
criminólogos (Horvitz, 2012) en un pueblo del norte de Inglaterra, con el cual se pretendió investigar qué quiere decir la gente cuando habla de delito, pues se observó que:

Los aldeanos mostraban un altísimo nivel de miedo al delito aunque las estadísticas policiales no daban cuenta de un correspondiente incremento de la actividad delictiva. A través de entrevistas a los pobladores, los autores del estudio descubrieron que el incremento del miedo decía más bien relación con la percepción más amenazante del propio entorno. En particular, estaba relacionado con una corriente de inmigrantes que se instaló en dicha área urbana, antes muy homogénea, fenómeno que fue sentido por todos de un modo disruptivo, como "algo" peligroso para su identidad como comunidad (Horvitz, 2012, p. 102).

Como se advierte, la representación del mal impulsa la creación de medidas de control con tinte represivo, para castigar y expulsar a los indeseados, vagos o malvivientes, que, independientemente de la etiqueta que se utilice, son víctimas no solo de una situación socioeconómica indeseable, sino de estereotipos que responden a los peores prejuicios de cada sociedad (Zaffaroni,

veces, escuchando a los jóvenes hablar de sus pueblos, se diría que en estos no hay ningún inmigrante, pues ni se les menciona ni se les tiene en cuenta para nada, casi como si fueran invisibles, o como si no existieran. Pero en otras ocasiones, la forma en que se habla de ellos parece indicar todo lo contrario, mostrando hasta qué punto esos inmigrantes llaman poderosamente la atención de los autóctonos, que se fijan en detalle en todo lo que tiene que ver con estos, aunque casi siempre "de lejos", precipitada y superficialmente, sin llegar a conocerlos de cerca. Esas supuestas diferencias de los inmigrantes tienen mucho más que ver con la posición social de las personas que con unos supuestos rasgos fenotípicos o "raciales". No es en absoluto casual que sea a los miembros de grupos sociales desfavorecidos a quienes se somete a una observación más minuciosa, hasta encontrar las supuestas marcas de su "diferencia" por pequeñas que sean, hasta el punto de que puede afirmarse que más que de una observación se trata, por decirlo en términos futbolísticos, de un férreo marcaje al equipo contrario. Al respecto véase Strohmayer (2005).
2005). Así pues, la reacción instantánea es aumentar las medidas de securitización fronterizas para combatir a los extraños objetos de peligro, que por necesidad, mas no por elección, terminan mayoritariamente habitando las peores zonas, que además de "peligrosas" (Mike, 2003) son habitadas por la "plebe", hecho indiscutible, como manifiesta Wacquant (2010), que criminaliza la pobreza.

\section{HAITÍ Y REPÚBLICA DOMINICANA TENSIONES IRRECONCILIABLES}

Si se recorre el escenario latinoamericano el pretexto es cada vez peor. La relación existente entre Haití y República Dominicana marca resistencias irreconciliables, no solo por el fiel e histórico rechazo de los dominicanos respecto a sus vecinos haitianos, sino por el racismo y xenofobia que incorpora de modo fehaciente dicha tensión.

Escenario en el que se entrecruzan relaciones históricas de poder y subordinación, pues lo que prima es inculcar el hábito de la obediencia y el respeto a la jerarquía. En efecto, "las formas de dominación basadas en la premisa o en la pretensión de una inherente superioridad parecen depender enormemente de la pompa, las leyes suntuarias, la parafernalia, las insignias y las ceremonias públicas de homenaje o tributo" (Scott, 2000, p. 81). Que en este caso, se emplearon para justificar la violencia de Estado; elementos que pueden identificarse en el desarrollo ideológico del antihaitianismo -predominante en el régimen de Trujillo en República Dominicana- lo cual como consigna, parece aún no desaparecer, porque el programa se repite en nombre de un actuar jurídico.

Tras el terremoto que sacudió a Haití el 12 de enero de 2010, pese a las grandes pérdidas, el famoso tele-evangelista estadounidense Pat Robertson, se apresuró a decir que,

[...] la tragedia era causa directa del pacto con el Diablo. A través del cual los fundadores 
de la nación caribeña habían obtenido la independencia de la Francia napoleónica, y que para probar su teoría solo había que comparar Haití con su vecino, República Dominicana (Indiana, 2013, 9 de octubre).

Según Robertson, un ejemplo de "prosperidad", "gracias a que la nuestra no es una República de satánicos" (Indiana, 2013, 9 de octubre). El lema se repite: "la miseria es un mal y el portador del mal es asimilado al mal mismo" (Izco, 2010, p. 689).

Con la tragedia, considerada como la peor catástrofe humanitaria conocida hasta entonces, no coincidió una convincente y exitosa ayuda humanitaria, como sí una sociedad del espectáculo, prueba de ello son las palabras del ya citado Robertson, cual mesías enviado por Dios.

El camino a seguir del país más pobre del hemisferio occidental (Movimiento sociales, 2009), quedó echado a la suerte cuando no se consultó directamente al pueblo haitiano, sobre el plan de reconstrucción producido por un grupo de 300 tecnócratas, que se saltó un proceso amplio de consulta con los actores sociales haitianos (Movimientos Sociales, 2009). Principalmente cuando las condiciones socioeconómicas de la población haitiana antes del terremoto, indicaban su alto grado de vulnerabilidad. Cabe destacar que el $72 \%$ de los hogares vivían con menos de dos dólares por día (Santos, 2009).

Pese a dicho contexto, por una serie de acciones en cadena, la comunidad haitiana sigue afectada por el "mal". Evidentemente, Robertson no se equivoca; el mal está directamente personificado, pero ahora en nombre de la justicia, cuando un medio millón de personas quedarán apátridas por una sentencia del Tribunal Constitucional (TC) dominicano que, el 23 de septiembre del 2013, se pronunció para ratificar que no se reconocerá la nacionalidad a los hijos de padres extranjeros en situación migratoria irregular, nacidos a partir de 1929 en República Dominicana. Contexto que por esencia, perjudica a todos los dominicanos que no quieren ser reconocidos legalmente por ser descendientes directos de haitianos.

En palabras de Indiana Hernández (9 de octubre de 2013), la maldición que ahora se cierne sobre los haitianos es producto de artilugios más potentes, siniestros y escurridizos que los que se hacen acompañar del tambor. Esta magia, como otros señalan, "es la que se ampara en la ley para justificar un racismo despiadado. Ya la temían las víctimas del holocausto esclavista, quienes durante generaciones le vieron la cara a esa maldad que la avaricia habilita en los hombres" (Hernández, R. 2013, 9 de octubre, El país).

Uno de los mayores crímenes cometidos durante la tiranía del generalísimo Trujillo, fue "la matanza indiscriminada de haitianos en 1937, en la que se dice, según Vargas (2013), varias decenas de miles de estos miserables inmigrantes fueron asesinados por una masa enardecida con las fabricaciones apocalípticas de grupos nacionalistas fanáticos". (Vargas, 2013, 3 de noviembre, El país).

En efecto, fueron hechos primigenios en la consolidación de Trujillo como gobernante, el exterminio de la oposición interna, la destrucción de los partidos políticos de oposición y la formación de un partido único de corte fascista. También el control y monopolización del aparato productivo, la matanza de inmigrantes haitianos, el simulacro de apertura democrática en los años cuarenta y el establecimiento de gobiernos títeres (Sención, 2012). Por ende, cuando se trataba de exterminar, porque convenía suprimir a todo cuanto estorbaba, no había impedimento alguno, solo bastaba con publicar la noticia de un encuentro entre la fuerza pública y los merodeadores haitianos (Almoina, 2003).

Tu naciste cuando "el corte" me decía mi madre y no querían decirme lo que estaba pasando, porque yo estaba en el "riesgo" y pensaban eso iba a hacerme mucho daño. Pero en casa de tu abuelo (Julio Grullón) donde yo estaba pasando el puerperio, había 
una sirvienta haitiana llamada Artemisa, que había desaparecido y yo preguntaba ¿Qué pasa con Artemisa? ¿Dónde está Artemisa? Y tuvieron que decírmelo.

Lo que pasaba era, que Julio Grullón, había escondido su sirvienta haitiana, para evitar que la mataran, en el acto de barbarie más repugnante de nuestra historia. Durante una semana, cualquier habitante de la zona fronteriza, particularmente en la Línea Noroeste, que pareciera haitiano, era pasado a cuchillo sin preguntar nada, fuera anciano, mujer o niño. Cuando había alguna duda sobre si era dominicano, se le pedía que dijera la palabra "perejil", si el acento lo delataba, ahí mismo los sables "gallito", entraban en acción. Trujillo soltó presos delincuentes y los envió a la frontera para que participaran en la masacre $y$ de paso se quedaran con las propiedades de los haitianos muertos, o que despavoridos, lograban escapar cruzando la frontera.

En enero de 1938, Julio Grullón tomó a Artemisa y personalmente la llevó a Dajabón, la vio cruzar la Masacre y desaparecer en Haití. Jamás se supo de ella. En Montecristi quedó Sóntire, dominicano, su compañero sentimental, testigo de lo ocurrido, pero incapaz de relatar nada, pues quedó trastornado mentalmente, incoherente por el resto de sus días, por los sucesos de aquella fatídica semana de octubre de 1937. Él merodeaba la tienda de mi abuelo, quien piadosamente le pasaba un semanal, para que pudiera subsistir (Rodríguez, 2010, 11 de septiembre).

Ese 28 de septiembre de 1937, en la mañana, se inició el exterminio de los residentes haitianos. "Militares y algunos presos de confianza mataban a los niños, hombres y mujeres, con cuchillos, palos y machetes, con la intención de que pareciese un motín efectuado por campesinos dominicanos. Entre 12 mil y 25 mil haitianos fueron asesinados" (Mejía, 2008, p. 49). Aunque no se sabe con exactitud, cuántos haitianos pudieron perecer en aquel entonces.
Hoy, cual Alemania nazi, se habla de la cuestión haitiana como el "problema haitiano", crisis humanitaria llamada por la Organización de las Naciones Unidas (ONU); que encuentra completa legitimación en el pronunciamiento del TCRD, pues mejor "solución" al "problema haitiano" no podía encontrarse; la sumisión al "discurso oficial" (Cruz, 1998, p. 83) está hecha y no da señales de marchar hacia atrás.

En el pasado se intentó separar a Haití de República Dominicana, tras la decisión de España de abolir la dominación en Santo Domingo, convirtiéndolo en Estado independiente del Haití español en 1821, sin embargo, fue una independencia momentánea, pues la ocupación haitiana estuvo presente durante 22 años ligando la historia de ambos pueblos durante toda una generación (Moya, 2001a). Disputa que, en tiempo actuales, parece no tener fin, aunque ahora no es por territorio, sino por permanecer drásticamente separados y con el menor contacto posible, pues los "mulatos libres" de la sociedad dominicana presentes a principios del siglo XIX, que se consideraban más cerca a los españoles que de los antiguos esclavos (negros) de quienes descendían, no quieren parecerse al Haití pobre "engendrado del mal", pues la historia ya lo ha catalogado como "a very hell of horrors" (Davis, 2001, p. 4).

En consecuencia, el axioma se mantiene: "lo importante era no ser totalmente negro, o al menos lo suficientemente no negro como para no ser confundido con un haitiano" (Moya, 2001a, p. 21). Como se evidencia yace en el presente vicisitudes que no abandonan el tiempo pasado; la era de Trujillo lo ilustra con bastante claridad. En tiempos actuales, pero revisando el pasado, se observa la sangre manchada y no solo haitiana, sino también dominicana, por un dictador que podía manipular al igual que Hitler a la masa que lo seguía; las circunstancias estaban a su favor porque mantenía al pueblo dominicano aislado lo más posible del mundo exterior. Para ello usaba las herramientas dadas por el poder, para "poder hacer". Trujillo se valió de todos los métodos para lograr la absoluta dominación del país, con el control completo de los medios de 
comunicación limitando la libertad de expresión (Almoina, 2003). Si bien es cierto que tomó el poder mediante el fraude y el asesinato,

[...] lo mantuvo de la misma manera pero apoyado por los militares, muchos intelectuales, el Partido Dominicano (dirigido por él), la cúpula de la Iglesia Católica, la prensa y el gobierno de Estados Unidos, que solo le quitó el respaldo cuando vio que su dictadura comenzaba a derrumbarse a finales de los años cincuenta (Sención, 2012, p. 8).

La masacre es entonces, la evidencia más contundente de esta supuesta hostilidad que desde antaño se siente en contra de los haitianos. De esta manera, "tanto el antihaitianismo como la masacre han llegado a estar íntimamente ligados en la memoria del pueblo" (Morales, 2009, p. 65). Ello demuestra el hecho de que

[...] entre las muchas tradiciones heredadas por la sincrética sociedad dominicana, esta magia sobrevive de manera especial. Tras casi un siglo de trabajos forzados y maltratos de todo tipo, queremos arrebatarle el derecho a la nacionalidad a los hijos que los haitianos tienen en la República Dominicana (Morales, 2009, p. 65).

Conforme a lo anterior, es necesario plantear el siguiente cuestionamiento: ¿cuál es la razón para seguir excluyendo a un pueblo que ha vivido décadas tras décadas la negrura de su color hasta la esclavitud moderna en las peores labores escenificadas por trabajos mal remunerados? En suma, en el yerro de las modernas democracias permanece latente el horror de la tiranía. Precisamente el examen de la masacre haitiana de 1937 ,

[...] revela cómo para racionalizar el presente se construye el pasado y se inventan tradiciones. En este caso, el concepto de Haití como un enemigo imaginario fue el elemento clave de una nueva identidad basada en una nueva representación del pasado (Derbi \& Turits, 1993, p. 65).

\section{El pecado de nacer haitiano: un adiós a los derechos humanos}

"Yo me crié aquí y nunca he ido a ningún país", dice Juliana, quien nació y aún vive en el batey de los Jovillos, un barracón que comparten más de 20 familias de braceros de origen haitiano, en el municipio agrícola Yamasá, a hora y media de camino de Santo Domingo, la capital. Juliana tuvo una partida de nacimiento dominicana, que le fue entregada a su padre cuando la presentó ante el registro civil utilizando su carné de trabajador del Consejo Estatal del Azúcar (CEA). En 2007, cuando Juliana había cumplido la mayoría de edad e intentó obtener su primera cédula dominicana, las autoridades del registro se negaron y retuvieron sus documentos alegando que sus apellidos eran "sospechosos", pues eran apellidos haitianos (Primera, 2013, 20 de octubre).

El "problema haitiano", o dicho de otra forma, el antihaitianismo forma parte de la historiografía dominicana; que se encuadra ya bastante incluso, en El otoño del patriarca, relato de Gabriel García Márquez sobre la vida de un tirano, época donde aún los negros eran contagiosos, y el poder del déspota parecía ser el mismísimo poder de Dios.

Sobre el particular, hoy se desarrollan demonios tiránicos con el antifaz de la democracia. No siendo suficiente, ahora se les niega un derecho humano básico, como lo es el derecho a la nacionalidad. La sentencia TC0168-13 del TC dominicano, es prueba de ello. Con un festín jurídico bastante convincente y bien argumentado, devela la manera como se mantiene el poder de la democracia bajo la tiranía.

La accionante Juliana Deguis Pierre, pese a ser dominicana de nacimiento y haber vivido toda su infancia en el municipio de Yamasá, provincia de Monte Plata, como se desprende de los hechos narrados en la sentencia; compareció ante el centro de cedulación de su provincia para solicitar por primera vez su cédula de ciudadanía, pero la misma en el acto se le negó con el retiro del 
acta de nacimiento, porque sus apellidos eran sospechosos, pues son de origen haitiano. La predicción está dada, sea como sea se confiesa tolerar la maldad, pero no la insensatez, como diría Arteta (1998):

Esta es capaz de causar más nuestro desagrado que aquella. Y es que la indignación, un efecto que acompaña la virtud de la justicia, goza en la actualidad de un escaso prestigio que la sitúa muy próxima a la intolerancia. Su gesto excesivo y apasionado es bastante para condenarla o reprimirla como muestra del mal gusto o desmesura. Sí la tolerancia está reñida con la indignación (y, por eso mismo, con la auténtica compasión), seguramente se debe a que el mal no la conmueve o la conmueve menos (p. 62).

En un sin sentido, Lorenzo Jiménez de Luis, representante residente de la ONU, en República Dominicana, expresa que la única salida para resolver el "problema" de los indocumentados, es la implementación del programa de regularización que manda y obliga la sentencia emitida por el TC, respetando la soberanía nacional, los acuerdos internacionales y los "derechos humanos" (León \& Pérez, 2013, 8 de noviembre). Por otro lado, la portavoz de la Oficina de la ONU, Ravina Shamdasani, manifestó que la decisión del Tribunal es inapelable, al dar a la Junta Nacional Electoral un año para elaborar una lista de personas a las que se les debe retirar la ciudadanía; aunque en el acto, la sentencia puede dejar a esas personas en un limbo constitucional y sin acceso a servicios básicos, para los que se requieren documentos de identidad.

No obstante, el fallo judicial encuentra legitimación en entes internacionales, entre ellos, la Unión Europea (UE) -reconociendo la validez del dictamen del TC, con el efecto erga omnes que dicha decisión tendrá para los centenares de haitianos afectados con la medida-. Empero, la Comisión Interamericana de Derechos Humanos, reconoció que la medida es preocupante, y tendría un "impacto desproporcionado en descendientes de haitianos que son afrodescendientes" (Comisión IDH, 2013, 25 de noviembre).
La inhumanidad parece ser la voz cantante de la década actual cuando se presencia lo que argumenta el TC, en una sentencia que margina, aún más, a los haitianos: los tradicionales pobres $e$ ilegales y cuantos sacrilegios puedan ocurrirse, pues se requiere el desalojo de los "indeseados". En efecto, referirse a que los padres de la recurrente, Juliana Deguis, "son extranjeros y que de manera ilícita e irregular han inscrito a sus hijos en los libros de registro del estado civil es franca violación del texto constitucional vigente al momento de la declaración" (Tribunal Constitucional de República Dominicana, 2013, 23 de septiembre). Aludir que con el recurso de amparo la accionante ha pretendido

[...] dotarse de una sentencia con patente de corso para validar la violación de la ley $y$ en tal virtud reclamar a punta de astreinte un supuesto derecho [...], fundamentado en una inexistente atribución de que la violación a la ley es una fuente de derecho absoluto e incuestionable [...] (Tribunal Constitucional de República Dominicana, 2013, 23 de septiembre).

Argüir también, como lo hace la sentencia que, la entrega de la documentación requerida por la recurrida va en contra de lo que establece la Constitución y las leyes que rigen la materia; y que la Junta Central Electoral no está despojando de nacionalidad ni dejando apátrida a persona alguna, ya que tal y como determina la Constitución de la República de Haití de manera clara y tajante, en su artículo 11, "Posee la nacionalidad haitiana todo individuo nacido de padre haitiano o de madre haitiana, los cuales hayan nacido haitianos que no hayan renunciado a su nacionalidad al momento de su nacimiento [...]".

Basarse en que la Convención Americana sobre Derechos Humanos de 1969, decreta en su artículo 20 , que toda persona tiene derecho a una nacionalidad, la cual pudiera ser la nacionalidad del Estado en cuyo territorio nació "sino tiene derecho a otra" y que el derecho internacional fija y reconoce que el Estado no está obligado a otorgar su nacionalidad a los nacidos en su territorio, si estos tienen 
derecho a adquirir otra, según el criterio recalcado históricamente por la Constitución.

Replicar también que, el sistema de adquisición de la nacionalidad de la República Dominicana no se encuentra basado en el ius soli o en el ius sanguinis, sino que se trata de un sistema mixto en el que se conjugan y complementan ambos sistemas, por lo que es más fácil aprovecharse de una debilidad del sistema en un momento y obtener una inscripción fraudulenta que seguir los pasos que establece la ley para que un extranjero obtenga su nacionalidad, conforme a la ley 1683/1948; es la hipocresía hecha justicia. Si se tiene sangre haitiana por la venas, la justicia tendrá que ser ciega a los ojos de los desesperados.

Desde que comenzó la ocupación estadounidense en Haití (1915-1934), la industria dominicana del azúcar se mueve gracias a la mano de obra haitiana, con el consentimiento de las autoridades. Al día de hoy, en República Dominicana operan cuatro grandes ingenios y cada uno requiere de la fuerza de 5.000 braceros para poder funcionar. La paga que ellos reciben por el empleo riesgoso y duro de cortar caña de azúcar con machete, depende de su desempeño: las empresas pagan 200 pesos (poco más de 4,5 dólares) por cada tonelada cortada. Un bracero diestro, como el padre [de] Juliana Deguis Pierre, que tiene 58 años y trabaja en la zafra desde que tenía 15, nunca alcanza a cortar más de dos toneladas y media al día (Indiana, 2013a, 20 de octubre).

La hipocresía y la ceguera de la justicia nacieron gemelas, de eso no hay duda; es un llover sobre mojado, pues la era de Trujillo parece estar más viva que nunca levantada con ira como el leviatán para golpear a los súbditos; la ley vale para lo que se quiera que valga, pues hecha la ley hecha la trampa. Es inadmisible usar instrumentos internacionales de protección de derechos humanos, reconocidos por el derecho internacional de los derechos humanos, algunos de los cuales tienen el rango de normas de ius cogens, y por lo tanto, gozan de obligatoria e imperativa observancia, para tratar de justificar una sentencia que más que justicia constitucional, es una burla ante la cara no grata de la miseria.
Síntoma que como se ha descrito, no es la mejor amiga del sistema llamado mundo, donde los marginados deben excluirse por ser el estorbo del sistema, la carga engendrada del mal.

¿Dónde está el poder de la justicia emanado del derecho, y sobre todo, se insiste, por qué tanta inhumanidad? El coexistir se hace brutal y breve; las palabras de Jefferson llegan a oídos sordos:

Cuando un gobierno, sea cual sea su forma, se aleja de estos objetivos, el pueblo tiene derecho a cambiarlo o a abolirlo, y a establecer un nuevo gobierno que se base en estos principios, organizándolo en la forma que le parezca más adecuada para que le procure seguridad y felicidad (citado en Ziegler, 2006, p. 14).

La máxima expresión del pluralismo, la multiculturalidad, el respeto por la diferencia y los derechos humanos, hoy se refleja en la llamada democracia imperante en la mayoría de los Estados en la esfera global. No obstante, en clara contradicción, lo que se encuentra es que

[...] en las barriadas de chabolas de Asia, África y América Latina, púdicamente llamadas "hábitats insalubres" por las Naciones Unidas, en las que vive el 40 por ciento de la población mundial, las ratas disputan a las amas de casa la escasa comida familiar (Ziegler, 2006, p. 15).

Y aun así, la humanidad se desentiende ante el llamado de quienes quieren solo vivir con idignidad! Los haitianos han sido excluidos históricamente, ello lo demuestra el arma genocida de Trujillo, $y$ eso no hay que ni probarlo; pero el presente continúa siendo un arma mortal en la búsqueda de un vivir con dignidad. La salida hacia la vecina República Dominicana, es una vía para encontrar un mejor horizonte para no estar de por vida nadando en la miseria. iComiendo tierra! Si bien, en la década de Trujillo podría pensarse que había razones para entender el pensar y el sentir del antihaitianismo, reflejado con su ira en el poder, pues al igual que el nazismo -se 
introyectaron pautas a adoptar validadas por el colectivo que fielmente las seguía, fuese por temor o por sumisión ideológica- el antihaitianismo era útil, por varias razones:

Primero, servía como racionalización implícita de la masacre como un acto nacionalista que tenía que ejecutarse. Segundo, estos elementos pudieron ser útiles para garantizar el apoyo al régimen de Trujillo por parte de la pequeña élite antihaitiana, que resentía el poder económico y político sin precedente ejercido por Trujillo. Los miembros de esta élite veían a Trujillo como un tirano y déspota, mulato perteneciente a la clase baja de la sociedad. Tercero, Aunque el antihaitianismo no era prevalente en el momento de la masacre, muchos intelectuales dominicanos de aquel tiempo eran tenazmente antihaitianistas. De esta manera Trujillo utilizó una ideología perteneciente a una pequeña élite para darle justificación intelectual, tanto a la masacre como a su gobierno (Derbi \& Turits, 1993, p. 67).

Pero en la década actual, época de humanización del derecho, ambición presente cuando se institucionaliza la idea de primacía de la dignidad humana (Herrera, 2008), ideario vigente en la amplia gama de instrumentos internacionales sobre derechos humanos en el orden global que suponen que la humanidad se ha sensibilizado aún más, "frente a los ataques que cuestionan la dignidad del hombre frente a cualquier situación, ante cualquier persona y circunstancias" (Leal, 2008, p. 236), pues los derechos humanos son un elemento que le confiere legitimidad, seguridad y garantía, al orden social y político; de ahí que la dignidad humana se convierte en "la razón y la consecuencia de la lucha por la democracia y por la justicia" (Herrera, 2008, p. 14); es inadmisible hallar pronunciamiento en un TC, que sin modestia alguna, justifica su decisión falseando el objeto y fin para lo cual han sido creados los tratados internacionales sobre derechos humanos.
Si se relee a Mario Vargas Llosa (2013) en Los parias del Caribe, se podrá observar que en su opinión la sentencia del TC dominicano es una

[...] aberración jurídica y parece directamente inspirada en las famosas leyes hitlerianas de los años treinta dictadas por los jueces alemanes nazis para privar de la nacionalidad alemana a los judíos que llevaban muchos años (muchos siglos) avecindados en ese país y eran parte constitutiva de su sociedad (3 de noviembre).

No es de desconocimiento que Hitler empleó conscientemente su guerra para desarrollar y, valga decir, perfeccionar el Gobierno totalitario (Arendt, 1998). Las leyes son políticas y una vez emitidas adquieren carácter jurídico. Las sentencias son jurídicas pero expresan un sentir político. Cuando una sentencia no es bien sustentada ni siquiera en lo jurídico, genera legítimas sospechas políticas. Reflexión que soporta Espinal (2013) cuando argumenta, entre otras cosas, lo siguiente:

Trujillo y Balaguer trajeron muchos haitianos a trabajar en los cañaverales en República Dominicana, y ambos se caracterizaron por conjugar la súper-explotación de la fuerza laboral haitiana con el antihaitianismo. Lo mismo hacen sus sucesores políticos, y por eso han creado este gran tollo migratorio. Igualmente, mantener segmentos poblacionales pobres, excluidos del derecho a la nacionalidad, y por tanto, del derecho al voto, facilita la estrategia de súper-explotación laboral y predominio político. Quienes no tienen derechos no pueden demandar, y por tanto, son desprotegidos. Y si quieren protestar, serán catalogados de malagradecidos $e$ indignos de vivir en territorio dominicano [...] (23 de octubre).

"La aberración jurídica", como la denomina Vargas Llosa (2013), es tan notoria, que el TC se salta el precedente jurídico de la Corte Interamericana de Derechos Humanos en un caso análogo -pero sí 
por el contrario justifica su decisión en los propios derechos humanos, sarcasmos junto con ironía-, pues ya los órganos del Sistema Interamericano se habían referido a un asunto similar en el año 2005, arguyendo en su momento, que la Constitución de República Dominicana, instaura el principio del ius soli para determinar quiénes son ciudadanos dominicanos. Por ello, la Comisión Interamericana (2005), en el caso de las niñas Yean y Bosico Vs. República Dominicana, señaló que, el Estado había obligado a las víctimas

[las niñas Yean y Bosico] a permanecer en una situación de continua ilegalidad y vulnerabilidad social, violaciones que adquieren una dimensión más grave cuando se trata de menores, toda vez que la República Dominicana les negó su derecho a la nacionalidad y las mantuvo como apátridas (Corte IDH, 2005, 8 de septiembre).

Con el no goce de los derechos derivados. $\mathrm{Si}$ bien, como explicó en la citada sentencia el abogado Frederick John Packer (2005, 8 de septiembre ), aunque los asuntos que se relacionan con la nacionalidad han sido por tradición de fuero estatal, la nacionalidad como término legal se define tradicionalmente con base en dos principios: el sanguíneo (o herencia familiar) y el de lugar de nacimiento; sin embargo, existen tratados internacionales sobre derechos humanos y Tribunales Internacionales -tales como la Corte Interamericana de Derechos Humanos y la Corte Internacional de Justicia- que han adoptado el principio de vínculo efectivo entre el individuo y el Estado para definir la nacionalidad. En consecuencia:

No es razonable solicitar documentos que demuestren el estado migratorio legal del padre o de la madre. Ya que solicitar documentos probatorios de un vínculo matrimonial o de un estado migratorio de los padres constituye una discriminación por origen y por pertenencia a un grupo social. Por tanto, "los documentos que demuestran la relación de los padres del solicitante con el Estado son irrelevantes, ya que el vínculo a demostrar es el existente entre el solicitante y el Estado" (Corte IDH, 2005, 8 de septiembre).

De evidenciarse una actuación jurídica contraria, no se estaría hablando únicamente de la privación del derecho humano a la nacionalidad, sino de normas rectoras como el principio de igualdad y no discriminación (Corte IDH, 2005, 8 de septiembre), que ostentan el calificativo de norma de ius cogens (Corte IDH, Masacre Plan de Sánchez vs. Guatemala, 2004, 29 de abril), por ser una categoría abierta que "se expande en la medida en que se despierta la conciencia jurídica universal" (Corte IDH, 2003, OC-18 \& Corte IDH, 2004). En esa medida, los Estados como lo ha ratificado la Corte Interamericana de Derechos Humanos (2003, OC-18) tienen la obligación de garantizar este principio fundamental a sus ciudadanos y a toda persona extranjera que se encuentre en su territorio, sin discriminación alguna, por su estancia regular o irregular, su nacionalidad, raza, género o cualquier otra causa; pues el estatus migratorio de una persona no se transmite a sus hijos, $y$ la condición del nacimiento en el territorio del Estado es la única a demostrarse para la adquisición de la nacionalidad.

Impugnando lo anterior, con excusa en la reforma que se ejecutó a la Constitución en 2010, el criterio de las autoridades dominicanas es que el principio jus solis (derecho al suelo) no ampara a los hijos de padres extranjeros, pues

[...] las autoridades judiciales han interpretado que si una persona no tiene residencia, se presume que está en tránsito, lo cual es una interpretación gramatical totalmente errónea. Según esta sentencia, miles de haitianos y sus hijos nacidos en República Dominicana-de acuerdo [con el] más reciente censo oficial, son unos 450.000- han vivido "en tránsito" hasta por ocho décadas (Primera, 2013, 20 de octubre). 
Al respecto, la Comisión Interamericana de Derechos Humanos manifestó en su escrito de observaciones preliminares el 6 de diciembre de 2013, producto de su visita a República Dominicana, que esta nueva interpretación del TC priva retroactivamente de su derecho a la nacionalidad dominicana a decenas de miles de personas que durante toda su vida habían sido consideradas dominicanas, muchas de las cuales fueron registradas por las autoridades competentes como nacionales dominicanos al nacer y a lo largo de su vida se les otorgaron otros documentos de identidad, como cédulas, carnés electorales y pasaportes.

Expresó igualmente que, a través de esta sentencia el Tribunal modificó retroactivamente la interpretación dada a los "extranjeros en tránsito" en las constituciones vigentes entre 1929 y 2010, las cuales establecían dicha categoría como una limitación para la adquisición del derecho a la nacionalidad por ius soli. La Comisión Interamericana, observó así mismo, que la desnacionalización afecta principalmente a personas de ascendencia haitiana nacidas en República Dominicana. Pues la sentencia 1682013 del TC tiene un efecto desproporcionado sobre estas personas, en virtud de que constituyen la mayor parte de la población migrante del país.

En consecuencia, la Corte Interamericana declaró que existe un vínculo indisoluble entre la obligación de respetar y garantizar los derechos humanos y el principio de igualdad ante la ley y no discriminación, y que este debe impregnar toda la actuación del Estado. Pero en el estudio que nos ocupa, la aberración se constata, al tratarse de una sentencia que desnacionalizó a un amplio grupo de personas nacidas en República Dominicana entre 1929 y 2010. Diversas fuentes lo han concluido, incluyendo fuentes gubernamentales, que serían por lo menos 200.000 las personas afectadas por esta sentencia, aunque el número no está definido; afirmó la Comisión (2013). Al respecto, la confesión de algunas víctimas llama la atención sobre el devenir de la medida:
"Yo en estos momentos ando viviendo una muerte civil; ando en la calle pero no existo", expresó una de estas personas. En el Batey Libertad, en la provincia de Valverde, la $\mathrm{CIDH}$ recibió el testimonio de una mujer que presentó un acta de nacimiento que certifica que ella nació en 1981 en el Hospital de Mao, en República Dominicana. Según su testimonio, no le han permitido registrar a ninguno de sus seis hijos: "fui al hospital a registrar a los muchachos, pero me dijeron que si no tengo cédula, no puedo registrarlos. Y voy a buscar la cédula a la Junta y me dicen que no tengo derecho a cédula porque soy extranjera. Y yo les digo "cómo voy a ser extranjera, si yo nací aquí y viví siempre aquî". Otra mujer que presentó su testimonio en Santo Domingo indicó que su hija nacida en 2013 no está registrada: "a mi hija menor no la quieren registrar; le niegan el registro porque dicen que su abuela es haitiana. Es como si no existiera”. Está apátrida. No es de aquí ni de allá (Comisión, 2013).

En defensa de los derechos humanos de poblaciones estigmatizadas, como la que aquí se referencia, el sociólogo Iñaki García (2003), plantea varios interrogantes provocando una adecuada reflexión: "¿Qué es lo que hace que se considere inmigrantes a personas que nunca han inmigrado? O ¿Cuánto tiempo ha de residirse en un país para dejar de ser visto como un inmigrante? [...]". Para encontrar una respuesta, la sentencia del TC no es una muestra alentadora, pues al parecer el ser inmigrante es una cuestión hereditaria que parece jamás perderse, máxime cuando se sigue llamando "inmigrantes" a personas territorialmente asentadas, calificativo que per se, resulta abusivo, pues supone definir su condición social a partir de una acción, la de inmigrar, que puede haber sucedido hace años y supone atribuir una identidad socialmente estigmatizada (pp. 27-30).

En suma, en la época de Trujillo no era factible el cuestionamiento sobre la función de los jueces que se supeditaban al tirano; lo que puede ilustrarse con los diversos casos típicos, que 
demuestran hasta qué punto era inexistente en Santo Domingo el llamado poder judicial, no ya su independencia, que sería cosa inaudita en aquella dictadura (Almoina, 2003). Empero, en la actualidad -pasada la actividad trujillista-, se goza de un andamiaje jurídico amplio en la defensa de los derechos humanos, vale decir entre ellos: la Convención Americana sobre Derechos Humanos o Pacto de San José de Costa Rica, la Convención para Reducir los Casos de Apatridia de las Naciones Unidas y la Declaración Universal de Derechos Humanos, en cuyo caso, promulga entre otras cosas, que los derechos humanos sean protegidos por un régimen de derecho, a fin de que el hombre no se vea compelido al supremo recurso de la rebelión contra la tiranía y la opresión. Por ello es paradigmático y contradictorio el actuar del TC, en un contrasentido evidente, respecto al alcance y desarrollo progresivo que deben ostentar, sin discriminación alguna, los derechos humanos.

El reto será entonces, que los órganos del Sistema Interamericano imposibiliten la ejecución de dicha sentencia, para salvaguardar los derechos humanos de un colectivo que ha sido, y sigue siendo excluido; pues las mismas palabras que se usan en la época actual, como el calificativo de "ilegal" (Dijk, 2005), son la forma moderna del "nuevo racismo" elegante, que evita las etiquetas con las que comúnmente se suele tratar a la población inmigrante, siendo implícitamente expresiones que transgreden y con alto contenido xenófobo "oculto". Así pues, parece que la sociedad seguirá teniendo enemigos -visibles o con piel de corderos- deambulando por ella (Jakobs, 2004).

Para no ir muy lejos, los controles policiales y fronterizos, cuando no la sospecha de terrorismo, aglutinan toda la sentencia sin juicio que podría recibir un inmigrante indocumentado, que de manera fulminante sería expulsado del territorio vagamente amenazado. A ello se debe que la sociedad de hoy por hoy comúnmente, legitime políticas extremas de seguridad; hipócrita política que diferencia nuevamente a los poderosos de los excluidos.
Nótese por ejemplo que, desde Roma hasta la actualidad, la persona del inmigrante es un buen candidato a enemigo, lo que es altamente riesgoso, en una época de revolución comunicacional, que facilita y promueve los desplazamientos como nunca antes, en un planeta donde las expectativas de vida entre los países difieren en forma alarmante y la necesidad de sobrevivir deviene motor de las migraciones masivas, al tiempo que la globalización promueve la libre circulación de capitales y mercaderías pero no la de humanos (Zaffaroni, 2006).

Will Kymlicka, profesor canadiense de filosofía política, aborda este tema en su obra Politics in the vernacular: nationalism, multiculturalism and citizenship (Política vernácula: nacionalismo, multiculturalismo y ciudadanía, 2003), para advertir cómo la movilidad al interior de un país que es un derecho humano básico, es contraria a la movilidad transfronteriza, precisamente porque se sobrevalora la movilidad individual respecto de la seguridad colectiva, la cual quedará protegida por los límites impuestos a la inmigración (Portilla, 2007). Por eso Bakunin, en palabras de Chomsky (1975) expresó con brillantes palabras que,

[...] la libertad es la única condición bajo la cual la inteligencia, la dignidad y la felicidad humana pueden desarrollarse y crecer; no la libertad puramente formal concedida, delimitada y regulada por el Estado, un eterno engaño que en realidad no representa otra cosa que el privilegio de algunos fundado en la esclavitud del resto (p. 4).

Es un hecho notorio que la libertad de circulación entendida como derecho humano básico que consagra, "la facultad de desplazarse o circular libremente por todo el territorio de un Estado, así como de entrar o salir del mismo y de elegir libremente en él su lugar de residencia" (Aguilar, 2010 , p. 15), es constreñida gracias al predominio de diversos contraderechos (Sagües, 2004); paralelismo acuñado para expresar cómo se minimizan los derechos por la retórica de "otros derechos", que operan para ser impuestos y 
legitimados, no como cualquier derecho, sino como supraderechos, vale mencionar entre ellos, el orden público, la seguridad nacional, y los derechos y libertades de los demás. Aunque en el pasado, doctrinalmente, la libertad de circulación se entendía como un derecho por excelencia universal.

Al respecto, tanto Suárez como Vitoria dignos iusinternacionalistas de mención, representantes del derecho internacional en su versión clásica, más conocida como ius gentium (Hoyos, 1998), formularon en su momento "las bases de los deberes internacionales de los Estados vis a vis inclusive los extranjeros, en el marco del principio general de la libertad de circulación y de las comunicaciones, a la luz de la universalidad del género humano. La sociabilidad y solidaridad humanas estaban presentes en toda la construcción doctrinal y la contribución de los teólogos españoles a la formación del derecho de gentes" (citados en Corte IDH, 2003, OC-18). Empero, letras muertas quedan en la historia, aunque el pasado amplio legado cultivó.

\section{REFLEXIONES FINALES}

La inmigración en sus variadas denominaciones (irregular, ilegal), no por ello moral y políticamente correcta, expeditamente se resume en una cuestión de fobia y racismo, más que de seguridad y soberanía nacional, lo que ciertamente restringe el contenido efectivo del derecho a la libre circulación. Es más,

[...] mientras que, paradójicamente, el derecho a entrar en un país está limitado a varias condiciones impuestas por el Estado receptor, el derecho a salir del país se puede ejercer sin ningún tipo de limitación. Contradicción que se encuentra al momento de analizar el derecho a la libre circulación de personas y las migraciones internacionales (Aguilar, 2010, p. 15).

Así, los capitales pueden producirse "donde los costos salariales sean menores y los trabajadores quedan presos en los territorios de sus países, sin posibilidad alguna de ofrecer su trabajo donde haya demanda y los salarios sean más altos" (Zaffaroni, 2006, p. 66).

En síntesis, lo antes expresado lleva a concluir que, la movilidad humana termina siendo un fenómeno con muchas facetas, o dicho de otro modo, es un fenómeno multicausal. Derivado de los diferentes matices que impulsan a los individuos en la esfera planetaria -en un mundo que dice estar globalizado- ${ }^{2}$, a salir casi de manera obligada de sus países originarios, pues ante un capitalismo que devora, la subsistencia a toda costa es la constante. Pero el riesgo latente es la sospecha que encara el país receptor, por la observación del otro como "enemigo". Circunstancia que fuerza al endurecimiento de las leyes de extranjería, que en todo caso, apuntan a la restricción de derechos humanos fundamentales, y, el pretexto será siempre la soberanía de la que son titulares todos los Estados.

Adicional al marco descrito, se ha generado en el mundo pérdida de valores, en donde el progreso, lejos de ser casi continuo, es mucho más parecido en su representación a la hoja de temperatura de un enfermo (Goytisolo, 1968); por tanto, se asiste a una especie de marginalidad avanzada, como sugeriría el sociólogo Wacquant (2005), pero no por falta de crecimiento económico sino por todo lo contrario.

2 Precisamente Sassen (2013, entrevista 29 de octubre), profesora de sociología de la Universidad de Columbia, apoya la idea de que las grandes ciudades de todo el mundo son el terreno adecuado para que una multiplicidad de procesos de globalización asuman formas concretas y localizadas. Pues las ciudades grandes también concentran una cuota cada vez mayor de poblaciones en desventaja -inmigrantes en Europa y Estados Unidos, afroamericanos y latinos en Estados Unidos, masas de ciudadanos arracimados en chabolas en las megaciudades del mundo en desarrollo-, podemos observar que se han convertido en un terreno estratégico para toda una serie de conflictos y contradicciones. En especial cuando los inmigrantes y las mujeres son actores importantes en las nuevas economías informales de estas ciudades; que absorben los costos de informalización de estas actividades. Cfr. Sassen (2013, entrevista 29 de octubre). Igualmente confróntese Sassen (2003, 2003a y 2007). 
Lamentablemente las promesas de la modernidad -la libertad, la igualdad y la solidaridad- siguen siendo, en palabras de Sousa (2005), una aspiración para la población mundial, pues hay un crecimiento que se caracteriza por ser desigual, un progreso que es inequitativo y trae consigo una inmensa regresión para los sectores más precarios de la clase trabajadora. Lo cual es de sobra producido precisamente por los sectores más amplios de la economía, no los más atrasados. Por ello aparecen formas de marginalidades que están por delante de nosotros y no por detrás (Sousa, 2005).

Desde una mirada crítica podría pensarse en la formación de modelos mediadores en estos conflictos sociales, por ejemplo, el hecho de que la economía deba ser controlada por la política. Pero no por cualquier política, sino por una comprometida no solo con la libre circulación de los capitales, sino también con la libre circulación de las personas; una política ajena a cualquier violación de los derechos recogidos en los textos de derechos humanos; una política, en fin, que aporte mecanismos para poder resistirnos, inmigrantes y residentes, a un orden global injusto y desigual, para contextualizar las polémicas en las que nos hemos visto insertos todos los que de un modo u otro estamos intentando concretar la idea de la dignidad desde el contexto del "nuevo espíritu del capitalismo" (Herrera, 2008, pp. 93 y 156), ante la falta de elaboración de un sistema de garantías de los derechos, que es finalmente el terreno más fecundo, no solo para la corrupción y el arbitrio (Ferrajoli, 1999), sino para fomentar la mundialización a costa de la exclusión.

Finalmente, Haití y República Dominicana son tan solo un ejemplo de la realidad que golpea a miles de inmigrantes por distintas razones, sean ellas históricas, políticas, económicas e incluso biológicas, lo cual acompaña normativas opresivas, $e$ incluso un racismo punitivo, para poder justificar acciones administrativas y jurídico-penales que intentan reducir, en el sentido más extenso, garantías y derechos que han sido reconocidos desde antaño producto de las luchas sociales. Con lo cual, se desconoce un actuar jurídico que abogue por el respeto de la dignidad humana y muy por el contrario las medidas restrictivas son la constante, retrocediendo a la par que se sustentan sólidos Estados de derecho.

\section{REFERENCIAS}

Agamben, G. (2010). Homo sacer. El poder soberano y la nuda vida. (Traducción: Gimeno Cuspinera). Valencia: Pre-textos.

Aguilar, L. (2010). El derecho humano a la libre circulación de personas en la migración internacional intracomunitaria. Lima: CAJ.

Almoina, J. (2003). Una satrapía en el Caribe. Santo Domingo: Letra Gráfica.

Arendt, H. (1998). Los orígenes del totalitarismo. (Traducción Guillermo Solana). Madrid: Grupo Santillana.

Arteta, A. (1998). La tolerancia como barbarie. Manuel C. (Coord). En Tolerancia o barbarie: Occidente ante el reto de la convivencia. (51-76), Barcelona: GEDISA.

Chomsky, N. (1975). Apuntes sobre el anarquismo, el marxismo y esperanzas sobre el futuro. Teoría a la práctica. Prólogo a la primera edición inglesa. En D. Guérin. El Anarquismo. Buenos Aires: Ediciones Utopía Libertaria.

Comisión Interamericana de Derechos Humanos. (2013, 2-6 de diciembre). Visita in loco a República Dominicana. Recuperado de http:// www.oas.org/es/cidh/actividades/visitas/2013RD/ ObservacionesPreliminares-RD-2013.pdf.

Corte Interamericana de Derechos Humanos. (2003, 17 de septiembre). OC-18, solicitada por los Estados Unidos Mexicanos. Recuperado de www.corteidh.or.cr/docs/opiniones/seriea_18_esp.pdf.

Corte Interamericana de Derechos Humanos. (2004, 29 de abril 29). Masacre Plan de Sánchez 
vs. Guatemala. Recuperado de http://www.corteidh.or.cr/docs/casos/articulos/seriec_105_esp.pdf.

Corte Interamericana de Derechos Humanos. (2005, 8 de septiembre). Caso de las niñas Yean y Bosico vs. República Dominicana. (Excepciones preliminares, fondo, reparaciones y costas). Recuperado de www.corteidh.or.cr/docs/resumen/ yean_bosico.pdf.

Cruz, M. (1998). Tolerancia o barbarie. Occidente ante el reto de la convivencia. Barcelona: Gedisa.

Davis, D. B. (2001). Impact of the French and Haitian Revolutions. En D. Pratick (ed.). In the impact of the Haitian Revolution in the Atlantic world (39). Columbia: University of South Carolina Press.

Derbi, R. \& Turits, R. (1993). Historia de terror y los terrores de la historia. La masacre haitiana de 1937 en la República Dominicana. Estudios Sociales, Cruzando Fronteras, 92, 65-76.

Dijk, T. (2005). Nuevo racismo y noticias. Un enfoque discursivo. En M. Nash, R. Tello \& N. Benach (eds.). Inmigración, género y espacios urbanos. Los tres retos de la diversidad (33-55). Barcelona: Bellaterra.

Espinal, R. (2013, 23 de octubre). Nacionalismo xenófobo conservador. Hoy Digital. Recuperado de http://hoy.com.do/nacionalismo-xenofoboconservador/autor/rosario-espinal/

Ferrajoli, L. (1999). Derechos y garantías. La ley del más débil. Madrid: Trota.

Focault, M. (2002). Vigilar y castigar. El nacimiento de la prisión. Buenos Aires: Siglo Veintiuno Editores.

Focault, M. (2007). El nacimiento de la biopolítica. Curso en el Collège de France: (1978-1979). Buenos Aires: Fondo de Cultura Económica.

García, I. (2003). Los hijos de inmigrantes extranjeros como objeto de estudio de la sociología. Anduli: Revista Andaluza de Ciencias Sociales, 3, 27-46.
Giorgi, A. (2006). El gobierno de la excedencia postfordismo y control de la multitud. Madrid: Traficantes de Sueños.

Goytisolo, J. (1968). Sociedad de masas y derecho. Madrid: Taurus.

Hardt, M. \& Negri, A. (2000). Imperio. Massachusetts: Harvard University Press.

Hernández, R. (2013, 9 de octubre). Magia Negra, el país. Recuperado de http://internacional. elpais.com/internacional/2013/10/09/actualidad/1381345925_372245.html.

Primera, M. (2013, 20 de octubre). Medio millón de apátridas por una sentencia del Supremo dominicano. El país. Recuperado de http://internacional.elpais.com/internacional/2013/10/20/ actualidad/1382 303313_233551.html.

Herrera, J. (2008). La reinvención de los derechos humanos. Valencia: Atrapasueños.

Horvitz, M. (2012). Seguridad y garantías: derecho penal y procesal penal de prevención de peligros. Revista de Estudios de la Justicia, 16, 99-118.

Hoyos, J. (1998). Apuntes sencillos sobre derecho internacional público. Medellín: Señal Editora.

Huntington, S. (2001). El choque de civilizaciones y la reconfiguración del orden mundial. Buenos Aires: Paidós.

Hernández, R. (2013, 9 de octubre). Magia negra. El País. Recuperado de http://internacional. elpais.com/internacional/2013/10/09/actualidad/1381345925_372245.html

Izco, T. B. (2010). Reseña a la obra de Gaulejac, Vincent. En Las Fuentes de la Vergüenza. Clínica e Investigación Relacional, 4(3), 685-705. Recuperado de http://www.psicoterapiarelacional.es/Portals/0/eJournalCeIR/ V4N3 2010/Cl\%C2\%A0sicos-15_Las-fuentesde-laverguenza_V_Gaujelac_BTomas_CeIRV4N3.pdf 
Jakobs, G. (2004). Dogmática de derecho penal y la configuración normativa de la sociedad. Madrid: Thomson-Civitas.

Leal, J. (2008). Un estudio de las actuales medidas de seguridad y los interrogantes que plantean en la moderna dogmática del derecho penal. Navarra: Thomson-Aranzadi.

León, V. \& Pérez, R. (2013, 15 de noviembre). ONU y UE reconocen la validez del fallo del TC. Listin Diario. Recuperado de http:/www.listin.com.do/ la-republica/2013/11/7/298760/ONU-y-UE-reconocen-la-validez-del-fallo-del-TC\#.UnzWnh6BImQ

Lucas, F. (2005). Nuevas estrategias de estigmatización. El derecho, frente a los inmigrantes. En G. Portilla (coord.). Mutaciones del Leviatán. Legitimación de los nuevos modelos penales (205-218). Madrid: Akal.

Mejía, M. (2008). La prensa escrita dominicana durante la "Era de Trujillo". Universidad de Miami, Florida: Monográfico de maestría University of Miami. Recuperado de http://www.monografias. com/trabajos-pdf2/prensa escrita-dominicana-eratrujillo/prensa-escrita-dominicana-era-trujillo.pdf.

Mike, D. (2003). Ciudad al cuarzo. Arqueología del futuro en los Ángeles. Rafael Reig (Trad). Madrid: Ediciones lengua de Trapo.

Morales, S. (2009). Almoina, un exiliado gallego contra la dictadura trujillista. Santo Domingo: Archivo General de la Nación.

Moya, F. (2001a). La independencia de Haití y República Dominicana. Historia del Caribe (9-38). Barcelona: Crítica.

Moya, F. (2001b). La República Dominicana, 1930-c. 1990. En Historia del Caribe (213-227). Barcelona: Crítica.

Movimientos sociales haitianos denuncian su exclusión total en conferencia de donantes para "reconstrucción" de Haití (2009). En Revista Estudios Sociales 150, Año 41, Vol. XL, 111-114.
Recuperado de http://bibliotecavirtual.clacso.org. ar/Republica_Dominicana/ces/20120813120949/ estsoc150.pdf.

Muñoz, F. (2002). El proyecto nacionalsocialista sobre el tratamiento de los extraños a la comunidad. En J. Díez. (Coord.). La ciencia del derecho penal ante el nuevo siglo (487-510). Madrid: Tecnos.

Muñoz, F. (2002a). Edmundo Mezger y el derecho penal de su tiempo. Estudios sobre el derecho penal en el nacionalsocialismo. Valencia: Tirant lo Blanch.

Naïr, S. (2010). La Europa mestiza. Inmigración, ciudadanía y codesarrollo. Barcelona: Círculo de Lectores.

O'neill, C.

Portilla, G. (2007). El derecho penal entre el cosmopolitismo universalista y el relativismo postmodernista. Valencia: Tirant lo Blanch.

Primera, M. (2013, 20 de octubre). Medio millón de apátridas por una sentencia del Supremo dominicano. El País. Recuperado de http://internacional.elpais.com/internacional/2013/10/20/ actualidad/1382303313_233551.html.

Rodríguez G. (2010) Matanza de haitianos II, (El Corte). Ayer y hoy. Recuperado de http:// juliomanuelrodriguez.blogspot.com/2010/09/ matanza-de haitianos-ii-el-corte.html.

Sagües, N. (2004). Derechos y contraderechos. A propósito de la violencia urbana. En J. Woischnik (dir.). Anuario de derecho constitucional latinoamericano (451-463). México D. F.: Instituto de Investigaciones Jurídicas de la UNAM.

Santos-Hernández, J. (2009). Terremoto en Haití. Un derrumbre de prejuicios. En Revista Estudios Sociales 150, Año 41, Vol. XL, 5-8. Recuperado de http://bibliotecavirtual.clacso. org.ar/Republica_Dominicana/ces/20120813 120949/estsoc150.pdf. 
Sassen, S. (2003). Contrageografías de la globalización. Género y ciudadanía en los circuitos transfronterizos. Madrid: Traficantes de Sueños.

Sassen, S. (2003a). El espectro de la globalización. Buenos Aires: Fondo de Cultura Económica.

Sassen, S. (2007). Una sociología de la globalización. Buenos Aires: Katz.

Scott, J. (2000). Detrás de la historia oficial. Fractal, 16, 69-92. Recuperado de http://www. mxfractal.org/F16scott.html

Sención, A. (2012). La dictadura de Trujillo (1930-1961). Santo Domingo: Archivo General de la Nación. Recuperado de http://agn. gov.do/publicaciones/libro/dictadura-trujillo1930-1961-augusto-sencion-villalona

Sousa, B. (2005). Renovar la teoría crítica y reinventar la emancipación social. Buenos Aires: Clacso.

Strohmayer, H., Coral, C. C., Castellanos, M. L., Ortega, I. G. B., \& Cánovas, A. P. (2005). Inmigración y diferenciación socioespacial: discursos, prácticas y sentido social del trazado de fronteras interétnico. En A. Pedreño \& P. Hernández (coords.). La condición inmigrante. Exploraciones e investigaciones desde la región de Murcia (273288). Murcia: Universidad de Murcia.

Tribunal Constitucional de República Dominicana (2013). Sentencia 0168 de 23 septiembre.
Vargas, M. (2013, 3 de noviembre). Los parias del Caribe. El País. Recuperado de http:/elpais.com/elpais/2013/10/31/opinion/1383233998_965346.html

Wacquant, L. (2005). Castigar a los parias urbanos. Oficios Terrestres, 17, 9-14.

Wacquant, L. (2007). La estigmatización territorial en la edad de la marginalidad avanzada. Ciências Sociais Unisinos, 43(3), 193-199. Recuperado de http://estudiosterritoriales.org/articulo. oa?id=93843301.

Wacquant, L. (2010). Castigar a los pobres: el gobierno neoliberal de la inseguridad social. Barcelona: Gedisa.

Zaffaroni, E. (2005). En torno de la cuestión penal. Buenos Aires: Bdef.

Zaffaroni, E. (2006). El enemigo en derecho penal. Estudios de criminología y política criminal. Madrid: Dykinson.

Zamora, J. (2005). Ciudadanía e inmigración. Las fronteras de la democracia. En A. Pedreño \& M. Hernández (coords.). La condición inmigrante. Exploraciones e investigaciones desde la región de Murcia (141-158). Murcia: Universidad de Murcia.

Ziegler, J. (2006). El imperio de la vergüenza. Madrid: Taurus. 